\title{
Peer to peers nurse managers' on supporting structures and systems they support in a resource: Constrained setting in Kenya
}

\author{
Simon Macharia Kamau \\ University of Kabianga, School of Science \& Technology, Department of Nursing Science, P. O. Box 5, Kapkatet 20214, Kenya
}

Email address:

smacharia@kabianga.ac.ke

To cite this article:

Simon Macharia Kamau. Peer to Peers Nurse Managers' on Supporting Structures and Systems they Support in a Resource: Constrained Setting in Kenya. American Journal of Nursing Science. Vol. 3, No. 6, 2014, pp. 126-132. doi: 10.11648/j.ajns.20140306.16

\begin{abstract}
This is an excerpt from a wider study on job description of nurse managers. Aimed to describe the experiences and perceptions of nurse managers towards the various factors that affect their roles as nurse managers in the hospital. Methods: This was a descriptive phenomenological peer research design, drawing lived experiences and perceptions of nurse managers. Study was done in February 2012 in a 600 bed public hospital in Kenya, purposively targeting all the 16 consenting nurse managers working in the institution: 13 took part in the mixed study, 6 in the focus group discussion and 2 in the face to face in-depth interview. Experiences and incidents collected became the unit of analysis into 5 key points. They were subjected to secondary analysis resulting in this qualitative report. Results: Problem Recognition: Nurse as employee, awareness of the demanding job, reflecting. Reflexivity on the part of the peer researcher. Some respondents disagreed that the job was satisfying to them. Some apprehension was obvious. Commitment: Accepting the role, altruism, duplicating and reciprocating. All respondents agreed that they did work that someone else was supposed to do. Exhaustion: High expectations, lowly appreciated, stagnating but not redundant, wearing out, frustration. Lack of recognition, supplies and equipment came out strongly as limiting factors in the performance of their complex roles. The nurse managers felt generally overworked and were not paid in commensurate. Discussions: There is great need to clearly outline the nurse managers' role in the hospital as their job description. Their roles were either complex, multidimensional or both. There is need to equip the nurse managers with leadership skills.
\end{abstract}

Keywords: Job Description(s), Peer Research, Nurse Managers, Kenya Nurses, Nurses Roles, Perceptions, Peer Research

\section{Introduction}

The nurse manager is responsible for development and supervision of nursing services in a division/department/unit managed by senior nursing officers. The nurse manager's job is key in facilitating patient care and in ensuring the quality of work life of the nursing fraternity. The nurse manager is given the responsibility to accomplish specified goals for the organization they work for. The manager must communicate a strong belief in the nursing team's contributions towards the goals of the organization [1].

According to Prof. Anna Karani, a renowned Kenyan nurse researcher, educator and writer; the shortage of nurses is acute in many countries, and there seems to be little hope of a quick change in this situation. It is therefore essential that this scarce resource is not only appropriately trained, but also creatively deployed. The first step in achieving these objectives she said would be to understand exactly what the job demands are [2].

Hospitals in Kenya and indeed throughout the region are in the midst of significant and even dramatic changes including embracing the Quality Management Systems model (ISO 9001:2008). The impact of these changes on the role of the nurse manager is just beginning to be identified and research in this area is limited [3].

Kleinman [4] studied nurse managers and made this observation, "nurse managers are often less well prepared to manage the business activities than the clinical activities". While Willy in [5] commented this about nursing from the Kenyan setting that, '...studies have shown that nurses are burdened with non-nursing duties.... which take away time which could otherwise be used for the core functions of nursing'.

Nurses are often appointed into the position of managers based on their clinical expertise, but they often lack confidence in topics ranging from human resource 
management, preparing and monitoring budgets, managing upward to senior colleagues, and using technology in everyday practice. One peer social media [6] (www.nursetogether.com) by nurses pointed out this reality, 'Nurse manager is sometimes a role that is thrust upon a nurse because nobody else wants the job...'

According to Ginette Rodger, then Chief Nursing Executive of Ottawa Hospital, in a positional statement dubbed-Nursing Leadership 2002 in Canada, 'leadership is the most pressing issue for the profession to act on' [7] Globally, the International Council of Nurses supports leadership development through projects like the Leadership for Change action learning program, locally through National Nurses' Association of Kenya (NNAK) [8].

\subsection{Justification}

Motivation for this study came from the author's (a nurse manager himself) concern for his own roles, perspectives and needs which may have had implications on his performance in general. This led to concern about other nurse managers. On more than one occasion the Chief Nurse of the study site had asked the nurse managers to come up with a job description for themselves, only one out of the 16 nurse managers submitted hers'.
It was an official requirement by QMS ISO 9001:2008 in this study area that every nurse manager be issued with a job description. This was as far as it went; being issued with one. As to whether or not it was cognizant with the job demands of the nurse manager was another thing all together. The issued ' $J D$ ' as was popularly known fell short of defining the scope. Reports, literature, book reviews and policy reviews from the wider inventory study $[9,10]$ offered an even wider scope with seemingly never ending expectations on the nurse manager. This ironically left the nurse manager with 'no job' description so to speak.

\section{Methodology}

This was a phenomenological peer research design drawing on lived experiences and perceptions of nurse managers. Polit referred in [11] mentioned some of the potential advantages of this design as: - ease of access, ease of recruitment, and the ability to get particularly candid, indepth data based on pre-established trust and rapport. Another potential advantage is the researcher's ability to detect subtle nuances that an outsider might miss or take months to uncover.

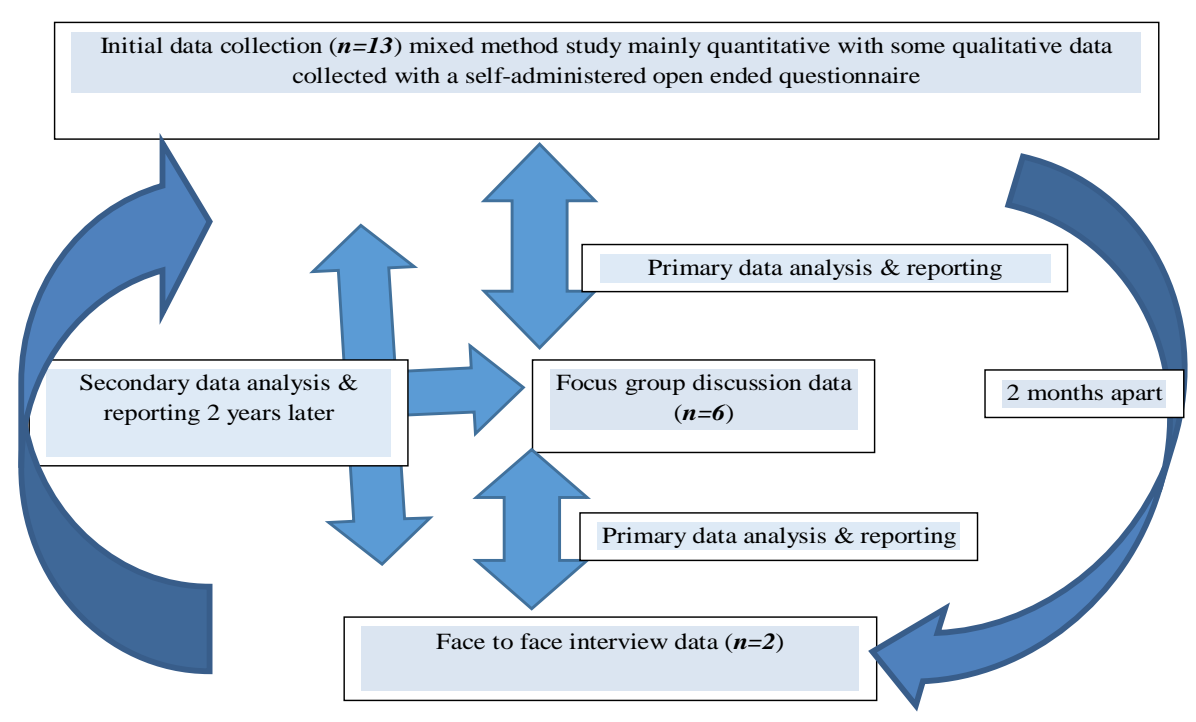

Figure 1. Emergent staging of sampling, data collection, analysis \& reporting framework.

The phenomenological researcher asks: what is the essence of this phenomenon as experienced by these people and what does it mean? [11]. Focus groups discussion capitalizes on the fact that members react to what is being said by others, thereby potentially leading to deeper expressions of opinion [11].

The study made use of purposive sampling all the nurse managers working in the hospital. Target population was a purposively selected, fairly homogeneous group of all the 16 nurse managers (13 took part in the mixed study a few weeks earlier), 6 subjects (2 males and 4 females) were conveniently selected for the focus group discussion while conveniently 2 key informants took part in the face to face in-depth interview.
Data gathering was done in February 2012. The setting: A venue of choice which was a familiar meeting point that acted as a conference room within the working environment during tea time $(10 \mathrm{am})$ ending at $1 \mathrm{pm}$. Arrangement was informal, some sitting on easy relaxing chairs or across a table. We employed the use of unstructured moderator interview guide, nonverbal observations, field notes and voice recording through a 3-hour focus group discussion.

The panel consisted of moderator/note taker I (a BSN staff nurse), note taker II (a monitoring \& evaluation officer who was also an experienced transcriber), observer/ non-verbal (a nurse counsellor). Recording of voice was allowed. Probing was done up to exhaustive exploration and completion of 
data (saturation).

A recorded formal face-to-face interview with two seasoned nurse managers (one male, one female) was done in one of their offices as it became necessary to to obtain varied views, confirm and enrich understanding on some themes that had emerged from the focus group. They were seasoned in the sense that they had mentored most of us who earlier on worked under them as staff nurses.

A shared view between participants and researcher added to the study's 'authenticity' and honesty. For rigor in the methodology member checks on site were allowed on voice recorded and summaries made with critical feedbacks although it added little to the accuracy of the transcript.

Each transcript was systematically checked for verbatim accuracy by listening to the audiotape while reading the notes that were taken in free hand, working with a peer reviewer. Some modified Colaizzi's procedural in phenomenological data analysis steps referred in [12] involved going back and forth on the protocols and returning to participants to validate some of the findings (see figure 1 above). Two participants were asked to review the study findings, and both agreed that the results captured their experiences.

Analysis was done thematically and in verbatim where necessary supplemented using ATLAS. ti 5.0 scientific software: Meaningful segments were identified, categorized, coded and portions of the text corresponding were subsequently retrieved. The final results have been presented in 5 key points. Some findings were triangulated with the quantitative results to from the wider study [9]. These were subjected to secondary analysis 2 years later by the same researcher to unearth some more hidden meanings as seen in figure 1.

\subsection{Delimitations}

A potential limitation of peer research, is the researcher's inability to be objective about group (or self) processes, which can result in unsuspected short sightedness about important but sensitive issues. The Observer-as-participant was described in the classics works of Goode and Hatt [13], was used whereby the researcher participates in a one-time slot but then takes a back seat to any further activities but would un-obstructively take notes. This researcher found it necessary to recruit an independent moderator (a staff nurse) to steer the discussions in the focus group discussion. This prevented "leading" the discussion. This effort it was hoped would create a platform where the rest of my colleagues would discuss freely.

Prior to, during and after this discussions the researcher maintained a follow on dated reflexive journal in an effort to bracket: interests, things that I took for granted, clarifying personal values, possible conflicts or lack of neutrality, remaining open and looking out for surprises. Any biases as such were also overcome by employing qualitative and quantitative data collection methods at different times [9]. The entity of the study area as an employer to the respondents and researcher; meant that a few aspects of the study findings would only be covertly disclosed.

\subsection{Ethical Approval}

Permission to expedite on the study was sought from the Institutional Research and Ethical Committee (IREC). Process consent was sought at each stage. The identifying features of the study site and subjects have been removed from this report, while most of the issues raised have since been addressed.

\section{Results}

The mean age of respondents was 40.9 years $(38.9 \%$ of the nurses were between 31-40years) the rest were over 40 years with $70 \%$ being female. Majority were married (only $10 \%$ were single), $70 \%$ had a Bachelors of Science in Nursing (BSN) degree while the rest had both Higher Diploma and Diplomas. Duration of engagement in this hospital mean was 6.3 years and 9.3 years as nurses since graduating. All those who responded were confirmed as Nurse Managers and none was in acting capacity [9].

\subsection{Conceptual-Framework}

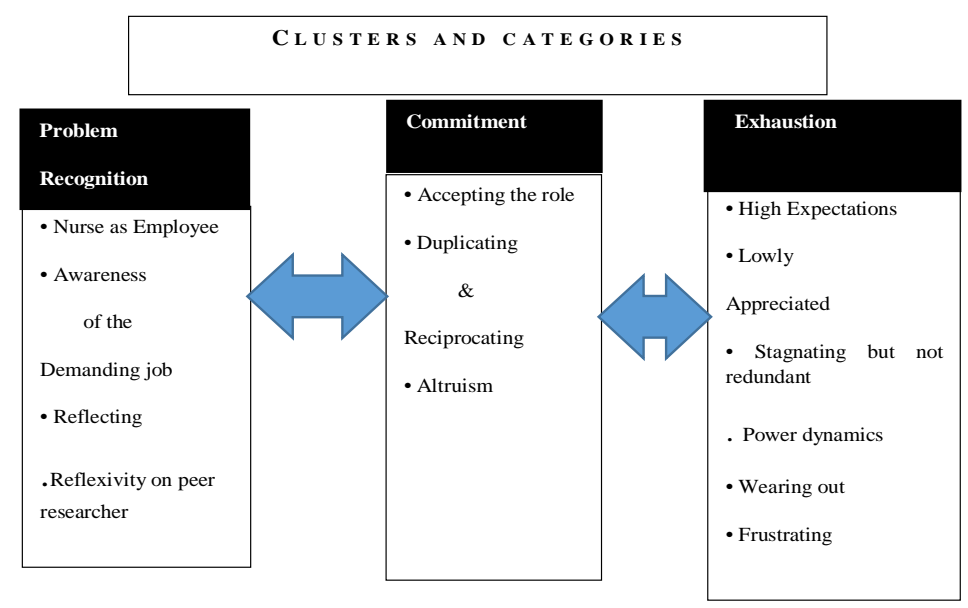

Figure 2. Conceptual framework on underlying assumptions of the perceptions of nurse managers towards their roles in the hospital. 
The conceptual framework shown in figure 2 below evolved as an emergent design reflecting on what was already learned [11] and not out of a prior theory. Therefore it captured the results as they came out. This will discussed later on. The original conceptual framework on these underlying assumptions of the perceptions of nurse managers towards their roles in the hospital were first used in the inventory study on job descriptions of nurse managers [9].

\subsection{Themes}

There were many common themes and reconstructed voices expressed across the focus groups and interviews emphasizing the need to elicit authentic self-expression of the interviewee [14]. These were observed when reviewing the data. A summary of the findings is given in 5 key points below: -

Key point 1. Challenges of the nurse manager position: Was the position interesting or just plain challenging? Mixed reaction responses: Representative quotes: 'I think given an opportunity to make some alterations; being a nurse manager is challenging rather than interesting. Challenging in the sense that there are a lot of responsibilities that are bestowed in a nurse manager especially now that we are moving in a direction where you can't recognise the roles of a nurse manager'.

'I think in a functional system, I could say it is interesting to certain extents. It appears that those responsibilities that others are shunning end up being handled by the nurse manager. So you spend most of your time addressing nonnursing duties'.

Interesting Position, representative quotes: 'Ok, I would say that it is actually interesting to be a nurse manager because considering the different situations that you will find yourself in and realising that you are able to advise, to supervise and even get through the challenges as my colleague is saying'.

'Getting through the challenges as he has mentioned, it is interesting. When you come on duty in the morning and at the end of the day reflect back on the aspects of services you have offered to the client, they are very varied and I think that is where the aspect of the job being interesting comes in. So, despite all the challenges that the nurse manager goes through, at the end of the day I would say that it is an interesting role'.

Challenging position: representative quotes-'It is more of a challenge than interesting because the issues handled are quite many, things that you may find that some are outside the nursing duties, one goes out to do administrative and even some involving the engineering sections because some of these items we use involve engineering. Those under the nurse manager expect him or her to know some of the issues revolving around engineering'. 'I also agree that it is more of a challenge than an interesting thing, because if what my colleagues have said. We all carry the burden of almost everything in the hospital'.

'The greatest challenge as a nurse manager has to be when you lack what you are supposed to have, for example equipment. You could be having maybe two $\mathrm{O}_{2}$ flow meters in a big unit. So you don't have the equipment required for the people on the ground to use, it becomes a very big challenge because they are supposed to work using these equipment and supplies, so that is a challenge'.

'Decision making on its own is challenging because being a player, you may make certain decisions that the management may not agree with. Such occurrences' affects the managers negatively'.

'My issue is recognition, when you are holding that title 'Nurse manager', some people may not recognize you, as the office expects you to play a big role when the doctors consider you just another nurse'.

'They have to come very early in the morning and the last people to leave in this hospital that is my observation'. 'In supplies department, there are shortages of items, we get information, pass it to the relevant authorities and make orders, but the process takes quite some time for supplies to come, the authorities above derail the process yet all the blame goes the nurse manager. There should be a bridge to communicate between the management to provide these things in time. The blame on the nurse manager by the authorities above is wrong'.

Conclusion to key point 1 :

Nurse managers tended to agree to disagree as to whether the job of the nurse manager was challenging or interesting. There appeared to be some apprehension about coping with challenges, perhaps they felt overwhelmed by some challenges and multiple roles.

Key point 2. Benefits that the position of a nurse manager offered (if any): What the nurse managers really felt about the benefits of this position: Representative quotes: 'I don't think there are any added benefits to this particular position apart from the fact that you attend meetings at some level otherwise no added benefits'.

'Job satisfaction working as a nurse manager, when your unit is running well and challenges that were there are addressed. By the end of the day you have that satisfaction'. 'So job satisfaction and self-motivation are the benefits considering that you could be earning less than the others. I am saying this because you might have some nurse managers who are at lower levels than their subordinate.'

Key point 3. Nurse manager: - The Roles versus the Job: The nurse managers strongly believed that duplication of roles existed in the then work setup. Representative quotes: 'As a nurse manager, I don't think that there should be duplication of roles in the unit. For example, client who has been given a bill which is erroneous and the person has a complaint, he/she will be told to go and see the nurse manager. As you try to go through that, you realise that you will be getting a challenge because of someone else's mistake but once the patient complains, they look up to the office of the nurse manager to solve such issues. It's a give and take'.

'It comes down to what we have said earlier that the position of a nurse manager carries lots of responsibilities 
carried from elsewhere, since you seem to understand the needs of a client, you tend to go an extra mile to make sure that certain requirements are supplied. At the end of the day you would have worked so hard and feel tired'.

Key point 4: There perception on what makes a good/outstanding nurse- Who an outstanding nurse was to the nurse managers: - The nurse managers thought basic but appropriate nursing knowledge and reasonable communication skills as traits that should be portrayed by an outstanding nurse

Representative quotes: 'I think it is that nurse who has knowledge about nursing and respond's completely to nursing needs of the client. Responses which are appropriate based on the required knowledge'.

'If I can add to that, should be a nurse that is able to provide quality services to patients which entails prompt services to the patient, being able to report on the patient, s/he should be adequate in terms of documentation-so that everything done is able to be reported'.

'Should be a person who is able to communicate with the patient, for everything that is done to the patient one should be able to get back and explain to the patient and let the patient understand and participate in terms of care'

Key point 5: There Perception on what should be the requirements for a nurse manager position

Special abilities that a nurse manager should have

Representative quotes: 'I would say that a nurse manager should have very many special abilities which I don't know whether it is possible to mention'.

'One thing, as a nurse manager you need to have very good human relations skills that is communication and interpersonal relationship, because as we have heard, you deal with a varied number of people from nurses to engineers, so you have to have the ability to communicate very well with this people for things to run. At the same time there is need for technical skills in nursing because when you supervise as a nurse manager you have to have the highest attainable skills for whatever area you are dealing with, because you will be supervising the students, supervising the new nurses, even these other nurses. So it is really necessary that you have the highest skills as far as the technical doing of whatever is required. At the same time, the issue of organisation, a nurse manager has to have good organisation skills because as we have said, your day has so many activities and to all these activities you really need to know how to organise them'.

'They have to have very high levels of decision making because they will be meeting with so many things that need immediate interventions. So as a nurse manager you have to have very high skills in decision making, so as to prioritize, so as to have whatever is to be done should be done carefully because it is something to do with the life of a patient'.

'Maybe I can add the issue of being observant, so that you are able to capture all the things that are happening to the unit, whether it is problems or staff that are coming on time and those not coming on time, you know? Really having that extra eye'
'I also think that networking is a very important aspect here, because as a nurse manager you are an actor between the people who require the service, management and those who provide resources. So for you to be able to adequately address the problems, you need to know the functions of relevant department in the hospital so that you can link this others pieces together'.

Educational requirements that a nurse manager should have 'I would say maybe, it should be the highest expected level, really because as we have said you have to have all the knowledge, and be good in decision, communication skills, so I feel it should be a very high level which can be attained, whether it is a Master's degree or a doctorate, whatever it maybe, but it should be utmost very high. It should not be separated between the highest level and the practicability of the work, they should be considered in all spheres, the highest level attainable and also very practical best performing 'coz you could have the papers but you are not performing, so it should actually be a highest level as possible but also be a very good performer regarding the issues to be handled'

'Education and practice should also be the case'.

'Most of the time I see people being appointed because they are at N1s level'. ( $\mathrm{N} 1=$ designation nursing officer grade 1 conventional acronym is NO1)

'At times, it is possible to have somebody who has attained the highest but attitude may end up affecting the behaviour of how somebody approaches responsibilities'.

Other issues that might be important in appointing nurse manager

Representative quotes: 'I think experience is something that should be considered so that to be appointed to manager at a particular place then you should have had experience in that field for quite some time'.

'Concurring with what Number three is saying, you should have at least rotated in all divisions. In the event that one is appointed in one division, the manager can be able to work well when there is changeover of staff. We also need to be gender sensitive, we have to mix females and males in different areas, so that when they have meetings they can interact and at least share ideas'.

'I tend to differ a bit in that, if you have the qualities of a nurse manager, as we have mentioned earlier, you can even be appointed as a nurse manager in a place you have not worked because basically you have the general training and everything, you also have the good skills we have talked about, communication, decision making, organisation. So I think you can still be effective even in a totally new place which you have not worked provided you have the basic requirements as we have said'.

'Secondly regarding the issue of gender, it is good to be in line with the other national policies on gender but at the same time that should not be the only reason; you should not be appointed because you are not common. Maybe they are not common for example; all the nurse managers might be women and so you want to bring a man, bring him because of the qualities. Gender should go hand in hand with the 
requirements. The position should not just be given out based on gender'.

What the nurse managers perceived as the next steps that would improve the position and improve output

- Nurse managers felt the need for the hospital management to review their remuneration and give substantive allowances and some sort of recognition.

- Nurse managers felt that there was great need to restructure the position. They felt that once the position was held for some time, preferably 2-3 years, one should be allowed to move to other exciting positions for growth without being viewed by the management in a bad light.

- More results could be realised if nurse managers oversaw operations that were related to their particular nursing fields. This would not only ease operations but would also facilitate the spirit of ownership and job satisfaction.

- Nurse managers need to be capacity built with much emphasis laid on leadership, administration and public relation issues. This would ensure that a nurse manager would be capable of handling the roles assigned to him or her and at the same time being able to correctly report and share with the rest of the hospital.

- Duplication of roles needed to be AVOIDED.

- Despite the fact that they did not have substantive allowances or recognition from other players in the hospital like doctors do, MOST of the nurse managers felt that they had experienced personal growth.

- There was a heated debate about the general progression and advancement of nurse managers. ALL the participants felt that the hospital management needed to come up with reasonable and clear criteria for progression and advancement of for the position of nurse manager. Suggestions for advancement included setting up intermediate positions between nurse managers and the hospital's Chief Nurse. They felt that creating such positions should be informed by the need, and would strengthen their progression.

\subsection{Surprises}

The biggest surprise that came out of the study was the fact that the nurse managers held the opinion that, the Title NURSE MANAGER in then setup of the hospital was a nothing but a vague title. This attributed to the fact that they saw no end after being in this position. They strongly felt that there was need to re- structure the position.

'It is sad to say this but I think the hospital has used as a way obtaining cheap labour. A way of getting maximum output with minimum labour' one participant said this indignantly.

The second big surprise that came out of the study was the fact that the participants held varied opinions on how the nurse manager should hired- some felt that the position should be advertised and make it competitive while others thought appointments should be made. 'This position would be more appropriate for it to be advertised so that those who have the interest can apply and that the appointing authority can have an opportunity to vet those who have applied when it comes to skills and experience we have discussed.'

'I think the process of appointment is better, considering this is an appointment that is happening after ones performance has been observed over time. Unlike if it was an advertisement because anybody else can apply. So how can we then verify this person who has come for an interview that s/he is effective as a nurse manager? I don't mind the appointment considering that they are appointing you after observation'.

\section{Summary on the Roles of a Nurse Manager}

The participants reiterated that the following broad roles should be the core duties of a nurse manager: To oversee patient care and ward/Unit management. Responsible for hospital linkages between the other nursing personnel and other sections (including the hospital management) to oversee educational and supervision functions. Other administrative and personnel disciplinary functions strongly related to their jobs

\section{Discussion and Conclusion}

As seen in figure 2 above the findings could be allocated to the following clusters and categories:

Problem Recognition: Nurse as employee- must support system, awareness of the demanding job, reflection on the part of the participants with sudden grasp of meanings vividly brought out. Some respondents disagreed that the job was satisfying to them. Some apprehension was obvious. Reflexivity (self-scrutiny) on the part of the peer researcher, a nurse manager himself.

Commitment: Accepting the role, altruism, duplicating and reciprocating. All respondents agreed that they did work that someone else was supposed to do.

Exhaustion: High expectations- getting less than needed support, lowly appreciated, stagnating but not redundant, wearing out, frustrations- some quite intense, power dynamics (inter and extraneous) between nurse-cadres and up against other health care disciplines. Lack of recognition, supplies and equipment came out strongly as limiting factors in the performance of their complex roles. They felt generally overworked and not paid in commensurate.

These findings agreed with [15] who a studied a wider scope of nurses in the Rift Valley Province and also with [16] case study of Kenya on Human Resources in Nursing (CHRIN) to International Council of Nurses. Both recommended that a number of studies needed to be carried out to shed more light on some critical areas in human resource dynamics in nursing and further that remuneration for health workers needed to be improved further to facilitate retention of nurses in the country. There was great need to clearly outline the nurse managers' role in the hospital as 
their job description. Their roles were either complex, multidimensional or both. There is need to equip the nurse managers with leadership skills.

No better way to tie all these together than the metaphor scripted and shared by one of the two seasoned nurse managers during a follow up interview which went like this;

'In Africa, we attempt to explain phenomena using analogies. A giraffe is one of the main attractions in subSaharan Africa. An elegant, stately animal. You should see it towering the heights of the savannah, chewing very tiny leaves from among the acacia thorns. But you have not seen anything yet! Wait until it takes to running, what a wonder. When it bends to drink from a pond, it looks so vulnerable. It appears to be something to do with its supporting structures or more likely the system it has to support. So is the nurse manager in the developing countries like Kenya'.

When requested to describe this more fully, it came out that the nurse manager, just like the giraffe is an indomitable figure in any health care setting. He/she bears the image of the hospital, going to great lengths/heights to ensure the smooth running of the institution amidst daunting challenges of a changing work environment. There seems to be an apparent disharmony between the supporting structures available for him/her most of the time as well as the system she supports.

Apparently this offered an insightful view of the findings. Morse [17] prominent nurse researcher posits qualitative researchers to be ready for insight and that they must have considerable knowledge about their data to be able to link them meaningfully.

Being a single site study of a small convenience sample, it may be risky to generalize the findings without replicating the study with another sample in other contexts. Perhaps some of the limitations mentioned in this study could be overcome by having organization(s) commission such studies through task forces as this may bring out salient issues.

\section{References}

[1] Maina, P., Karani A. Problems encountered by middle level nurse managers in ensuring quality nursing care in Kenyatta National Hospital, Kenya Nursing Journal 2004; (32) 2.

[2] Karani, A. 'Sustaining nursing leadership in the 21st century and beyond', Kenya Nursing Journal 2004; (32)1.

[3] Ngigi, A. 'Health sector policy overview paper'. Government Press, Kenya 2006.
[4] Kleinman, C. 'Leadership roles, competencies, and education: How prepared are our nurse managers?' Journal of Nursing Administration, 2003; (33) 9: 451-455.

[5] Willy, R. Documentation in Nursing care delivery: Which way for Kenya? Kenya Nursing Journal 2010; (39) 1.

[6] A Nurses' social network, Website accessed on 30th October 2014 at: www.nursetogether.com/

[7] 'Nursing leadership in a changing world', NursingNow Jan 2005; No.18, Canadian Nurses

[8] Association, National Nurses Association of Kenya (NNAK) Website accessed on 6th Dec 2012 at: www.nnak.or.ke/projects.php

[9] Kamau, S. Inventory on job description of nurse managers in developing countries, rising above the challenges and demands placed on the nurse manager in a changing work environment 2012. LAP Lambert Academic Publishing, Saarbrücken, Germany.

[10] Macharia, S. Nurse managers' perceptions towards the roles they play in a resource- limited hospital setting in western Kenya. Journal of Biology, Agriculture and Healthcare 2013.Vol.3, No.4.

[11] Polit, D., Beck, C. Nursing research, generating and assessing evidence for nursing practice; Wolters Kluwer/Lippincott Williams \& Wilkins, Philadelphia 2012

[12] Colaizzi, P. Psychological research as the phenomenologist views it. In Valle R. \& King M. (Eds.), Existential phenomenological alternative for psychology; New York: Oxford University Press 1978.

[13] Goode, W. \& Hatt, P. Methods in social research. International student edition. McGraw-Hill, Kogakusha Ltd 1952.

[14] Kalekin-Fishman, D. Review essay on Tom Wengraf, Qualitative Research Interviewing: Biographic Narrative and Semi-Structured Methods. Forum: Qualitative Social (FQS) Research 'Looking at Interviewing: From "Just Talk" to Meticulous Method' 2002. Available PDF: www.qualitativeresearch.net/index.php/fqs/article/download/800/1737

[15] Syallow, C. 'Job satisfaction among nurses and delivery of quality health services terms and conditions of service: a case study of Rift Valley', Kenya Nursing Journal 2010; (39).

[16] Rakuom, C. Nursing human resources in Kenya- case study, International Centre for Human Resources in Nursing (ICHRN) 2010.

[17] Morse, J. Insight, inference, evidence, and verification: Creating a legitimate discipline. International Journal of Qualitative Methods 2006. 